\title{
A COMPARISON OF ANALGESIA AND FOETAL OUTCOME IN TERM PARTURIENTS WITH AND WITHOUT LOW DOSE COMBINED SPINAL EPIDURAL LABOUR ANALGESIA
}

\author{
Manjunath $C^{1}$, Rebacca Jacob ${ }^{2}$ \\ ${ }^{1}$ Senior Specialist, Department of Anaesthesia, Aster CMI Hospital, Bangalore. \\ ${ }^{2}$ Academic Advisor, Department of Anaesthesia, Columbia Asia Referral Hospital, Bangalore.
}

ABSTRACT: STUDY OBJECTIVE: We aimed to find a safe method of labor analgesia with minimal side effects and toxicity in mother and fetus using combined 'low dose' spinal and epidural (CSE).

DESIGN: prospective case control study.

SETTING: Labour suite of a tertiary care hospital.

PATIENTS: study population included 120 pregnant women of ASA physical status I and II parturients in active labor who requested analgesia, 60 of these patients were given labour analgesia - 'GROUP T' and 60 of who underwent a delivery without labour analgesia -'GROUP C'.

MEASUREMENTS AND MAIN RESULTS: Maternal hemodynamics, degree of pain relief, duration of labour, fetal heart rate, Apgar scores, mode of delivery, intervention to relieve pain, Adverse effects because of procedure and drugs used were also noted. Low dose epidural analgesia does not prolong labour and does not increase the incidence of instrumental deliveries when compared to parturients undergoing delivery without labour analgesia. Even with the reduced dose of fentanyl the parturients had acceptable pain relief and a decreased incidence of intervention for pain. It does not cause more fetal depression when compared to normally laboring term parturients. 'Low dose' labour analgesia is a safe technique for painless labour with no harmful effects on the mother or baby and it does not significantly affect the obstetric outcome.

CONCLUSION: 'Low dose' labour analgesia is a safe technique for painless labour with no harmful effects on the mother or baby and it does not significantly affect the obstetric outcome.

KEYWORDS: Epidural, Bupivacaine, Fentanyl.

HOW TO CITE THIS ARTICLE: Manjunath C, Rebacca Jacob. "A Comparison of Analgesia and Foetal Outcome in Term Parturients with and without Low Dose Combined Spinal Epidural Labour Analgesia”. Journal of Evolution of Medical and Dental Sciences 2015; Vol. 4, Issue 90, November 09; Page: 15589-15592, D0I: 10.14260/jemds/2015/2236.

INTRODUCTION: Ideally pain relief with epidural techniques should be produced with minimum disturbance to the progress of labour or to sympathetic functions, sensory functions (proprioception) and motor functions of the CNS. Thus it is important that the obstetric anaesthetist strikes a balance between patient satisfaction by providing good analgesia and reducing motor block thus making the parturient participate in labour and decreases instrumental deliveries due to prolonged second stage. ${ }^{1}$

Labor pain, like other types of acute pain, has negative effects on the respiratory, cardiovascular, neuroendocrine and limbic systems. Several authors have attempted to find a safe method of labor analgesia without side effects on the mother and fetus. ${ }^{2-6}$ Combined spinal and epidural blockade is an effective means of providing analgesia during labor.

Bupivacaine is widely used to provide efficient epidural analgesia in labor. Dilute solutions of epidural local anesthetic combined with opioids may be used to minimize unwanted motor block. The amount by which fentanyl reduces local anesthetic dose requirement depends on the dose on fentanyl. ${ }^{7}$ We aimed to compare the efficacy and side

Financial or Other, Competing Interest: None.

Submission 21-10-2015, Peer Review 22-10-2015,

Acceptance 29-10-2015, Published 09-11-2015.

Corresponding Author:

Dr. Manjunath $C$,

D. No. 56, 1 $1^{\text {st }}$ Floor, $1^{\text {st }}$ Cross, $5^{\text {th }}$ Main, AGS Colony,

Anandanagar, Bangalore-560024.

E-mail: docmanju@rediffmail.com

DOI:10.14260/jemds/2015/2236. effects in mother and fetus of bupivacaine solutions containing fentanyl for labor analgesia by continuous epidural infusion. Fentanyl was added to bupivacaine as it reduces the local anesthetic requirement.

MATERIALS AND METHODS: This study was undertaken after obtaining approval from the Research and Ethics committee of the hospital. Written informed consent was obtained from all parturients. This study did not interfere with the normal obstetric management technique employed in this hospital.

This is a prospective case control study. The study population included 120 pregnant women 60 of who were given labour analgesia-'GROUP T' and 60 of who underwent a delivery without labour analgesia-'GROUP C'. Studied patients were ASA physical status I and II parturients with term singleton gestations and cephalic presentation who requested analgesia. When the patient was in active labor, achieving a cervical dilation of $3-4 \mathrm{~cm}$ and requested analgesia, a combined spinal-epidural technique was used. Parturients were excluded who were unwilling, any contraindication to regional technique, history of local anesthetic allergy, psychological or neurological diseases.

After establishment of good labour pains and cervical dilatation of $3-4 \mathrm{~cm}$, the parturients were placed either in left lateral position or in sitting position. The back was painted with povidone iodine and the area draped. The $\mathrm{L}_{2-3}$ interspace was identified and the skin over it was infiltrated with $2 \mathrm{ml}$ of $2 \%$ lignocaine using a 26G hypodermic needle. First spinal analgesia using a 26G Quincke's needle with fentanyl $15 \mathrm{mcg}$ diluted to $0.5 \mathrm{ml}$ with sterile saline was given and needle withdrawn. 
Next the L3-4 or L2-3 space was identified, a 18G Tuohy epidural needle was inserted. The epidural space was identified by the loss of resistance to saline technique. An epidural catheter was threaded $4-5 \mathrm{~cm}$ into the epidural space and fixed to the back of the parturient. A $10 \mathrm{ml}$ bolus of $0.1 \%$ bupivacaine was given followed by an infusion of $0.1 \%$ bupivacaine with fentanyl $1 \mathrm{mcg} / \mathrm{ml}$ at $6-12 \mathrm{ml} / \mathrm{hr}$.

The woman was given a left lateral tilt of 150 subsequently and was catheterized with Foleys catheter. Her vital parameters, progress of labour, efficacy of analgesia and fetal welfare were closely monitored.

The group $\mathrm{C}$ or control group of the study was those pregnant patients at term who underwent a normal vaginal delivery with intermittent boluses of tramadol to provide pain relief.

Mother's vital parameters, PR, BP \& SPO2 were recorded throughout the study at regular intervals as per proforma. Maternal hypotension (more than 10\% drop from the baseline) was treated by increasing the rate of IV fluids. Duration of I and II stage were noted in both the groups. Degree of pain relief-measured using VAS score during $1^{\text {st }}$ and $2^{\text {nd }}$ stage. Foetal monitoring-auscultation of FHS every $15 \mathrm{~min}$ was carried out to know the type of deceleration if any. APGAR score was assessed at 1, 5 and $10^{\text {th }}$ min. intervals following delivery in both the groups. Complications like fetal distress, meconium aspiration were noted and resuscitation to new born or shift to NICU was also noted. Patients who received drugs (tramadol) for pain relief was noted. Adverse effects because of procedure and drugs used monitored.

Descriptive statistical analysis has been carried out in the present study. Results on continuous measurements are presented on Mean \pm SD (Min-Max) and results on categorical measurements are presented in Number (\%). Significance is assessed at $5 \%$ level of significance. Cases of the samples should be independent Student $t$ test (two tailed, independent) has been used to find the significance of study parameters on continuous scale between two groups Inter group analysis) on metric parameters, Chi-square/Fisher Exact test has been used to find the significance of study parameters on categorical scale between two or more groups.

RESULTS: There were no differences between the groups with respect to demographic and labor characteristics. Gestational age. Height and weight, Parity, cervical dilatation at which analgesia was instituted, were compared and no significant difference was obtained $(\mathrm{p}>0.05)$.

Though a higher mean systolic and diastolic BP, pulse rate were seen in stage 2 in both groups, the vitals were significantly lower in Group $\mathrm{T}$ in both stage 1 and 2 when compared to Group C.

DISCUSSION: Epidural analgesia is used principally for pain relief during labour. It is estimated that in U.K. some $20 \%$ of all parturients now receive epidural analgesia for pain relief in labour. ${ }^{3}$ Safe and effective relief of pain during labour and delivery accomplished by the skillful use of epidural analgesia prevents the stress response in the mother.

Bupivacaine has stood the test of time as a bedrock of labour analgesia because of its longer duration of action and lesser degree of motor block for a comparable degree of sensory analgesia. ${ }^{8} \mathrm{Li}$ et al studied the efficacy of bupivacaine by reducing the concentration from $0.25 \%$ down to $0.0625 \%$ as bolus. ${ }^{9}$ Purdy et al compared $0.5 \%, 0.375 \%$ and $0.25 \%$ bupivacaine given as bolus doses. ${ }^{10}$

They observed that by reducing the concentration, the quality of analgesia was not affected, and lower concentrations of local anaesthetics minimized or prevented the motor block.

Studies by Reynolds revealed that only combination of opioids and local anaesthetics produced successful analgesia on initial and repeat administration and had a significantly quicker onset and longer duration of action. ${ }^{11}$ The combination of bupivacaine and an opioid has a synergistic effect on pain relief at lower doses of the either drug. ${ }^{12}$ The opioid most commonly used with bupivacaine is fentanyl. Recently alfentanil and sufentanil have been tried for labour analgesia without added advantage. ${ }^{13}$

Serutton MJ, Porter JS, Sullivan GO, did a study to know the impact of the introduction of low-dose epidural (bupivacaine $0.1 \%$ /fentanyl $2 \mu \mathrm{gm} / \mathrm{ml}$ ) compared with bupivacaine $0.25 \%$ for labour analgesia. The groups were compared for outcome of labour, quality of analgesia and any adverse events related to the epidural analgesia. There was a significant reduction in the lowdose group in the number of women requiring instrumental delivery. Maternal satisfaction regard to pain relief was high in both groups. ${ }^{14}$

We found in Group- T pain scores were between 7-10 before giving labour analgesia (CSE) which dropped to mean pain score of $0.67 \pm 1.00$ in the $1^{\text {st }}$ and $1.33 \pm 1.55$ in the $2^{\text {nd }}$ stage of labour. They thus had the appreciable pain relief in $2^{\text {nd }}$ stage of labour.

There is an expected increase in catecholamines in normal parturients. This increase in the mean pulse rate in the first and second stage of labour was seen in the normal parturients (Group C). After the establishment of the epidural injection in Group- T the mean rise of systolic and diastolic BP and HR in both stage 1 and 2 was not marked. We also observed a more constant heart rate in Group T. This suggests a wellcontrolled stress response with the use of CSE.

Reynolds et al also reported the combination of bupivacaine (10-12mg) with fentanyl $(80 \mu \mathrm{g})$ to effectively relieve first stage pain rather than bupivacaine or fentanyl used alone thus shortening the first stage. ${ }^{14}$ Unlike in Reynolds study we noted that the duration of the $1^{\text {st }}$ stage of labour was slightly more prolonged in Group T. However the obstetricians felt that labour was more prolonged in 7 parturients in Group $\mathrm{C}$ and only 1 parturient in group $\mathrm{T}$. These parturients underwent an LSCS.

James reported attenuation of endogenous oxytocin during second stage by epidural block which reduced the uterine contractility. However lower concentration of local anesthetics helps retention of pelvic floor sensation and is also less likely to affect endogenous oxytocin production and therefore will not unduly prolong labour. ${ }^{15}$

In the present study we found appreciably less incidence of prolonged labour (5.9\% in Group T and $41.2 \%$ in Group C) with the use of "low dose" CSE.

Fetal outcome have been assessed in a number of ways. Cohen $\mathrm{S}$ E et al measured neonatal condition by time to sustained respiration, APGAR scores, neurobehavioural scores and blood gas analysis. They reported no fetal heart rate variability when $2 \mu \mathrm{g} / \mathrm{ml}$ of fentanyl was used in the epidural space with bupivacaine, in varying concentrations. 
No infant required naloxone administration or endotracheal intubation. ${ }^{16}$ Reynold et al in their study did not report any change in the neurobehavioural or Apgar scores when upto $80 \mu \mathrm{g}$ fentanyl was given for first stage pain relief. 13 In our study, only Apgar score was employed to assess the newborns. At $1 \mathrm{~min} .10 \%$ in both Group T and Group C had an Apgar score of less than 6. At $5 \mathrm{~min} .1 .7 \%$ in Group T and none in Group C had an Apgar score of less than 6. At 10 min. all the patients in both groups had an Apgar score of more than 7. All were given oxygen and oral suction. 4(6.7\%) new borns in Group T and 2(3.3\%) new borns in Group C required bag and mask ventilation with oxygen. Though none of them neither required intubation nor mechanical ventilation, 2 (3.3\%) in Group T and 1 (1.7\%) in Group C were transferred to NICU for observation.

Wong $\mathrm{C}$ A et al found that neuraxial analgesia in early labour did not increase the rate of Caesarean delivery and it provided better analgesia and resulted in shorter duration of labour than systemic analgesia. ${ }^{17}$

Another study by Ohel $\mathrm{G}$ et al concluded that initiation of epidural analgesia in early labour following the first request for epidural, did not result in increased Caesarean deliveries, instrumental vaginal deliveries and other adverse effects, furthermore, it was associated with a shorter duration of the first stage of labour and was clearly preferred by women. ${ }^{18}$

We found the main indication for LSCS in group ' $\mathrm{C}$ ' was prolonged labour $(41.2 \%)$, CPD (11.8\%), DTA, FI, IUGR, RV $+\mathrm{VE}$, maternal exhaustion (1\% in each) and in group "T" CPD(35.3\%), DTA (11.8\%), fetal distress (23.5\%), MSAF (5.9\%). 'Failure to progress'a common indication for LSCS in patients with epidurals was similar in both the groups at $11.8 \%$. Thus in our study we noted that most of the parturients had a spontaneous vaginal delivery and the incidence of LSCS and instrumentation was similar in both groups indicating that the use of 'low dose' epidural analgesia did not increase the incidence of instrumentation.

The only complications noted in the test group were mild hypotension, corrected with IV fluids and itching which subsided in $30 \mathrm{mins}$ without treatment.

CONCLUSION: 'Low dose' labour analgesia is a safe technique for painless labour with no harmful effects on the mother or baby and it does not significantly affect the obstetric outcome.

\section{BIBLIOGRAPHY:}

1. Morgan BM, Kadim MY. Mobile regional analgesia in labour. Br J Obstet Gynec 1994;10:839-49.

2. Glosten B. Anesthesia for Obstetrics. In: Miller R D, editor. Anesthesia, 5th ed. vol. 2. New York: Churchill Livingstone, 2000: 2024-2086.
3. Zlatnik F J. Obstetric management of labor and vaginal delivery.In: Chestnut D H, ed. Obstetric Anesthesia. 2nd ed. St Louis: Mosby, 1999: 303-359.

4. Moir D D. Local anaesthetic techniques in obstetrics. Br J Anaesth 1986; 58: 747-759.

5. Bonica J J, McDonald S J. The pain of childbirth. In: Bonica J J,ed. The Management of Pain. 2nd ed. Lea, Febiger: Philadelphia, 1990: 1313-1343.

6. Lyons G, Columb M, Hawthorne L, Dresner M. Extradural pain relief in labour: bupivacaine sparing by extradural fentanyl is dose dependent. Br J Anaesth 1997; 78: 493497.

7. Argent VP. Treatment of severe tetany due to hyperventilation during labour with a mixture

of nitrous oxide, oxygen and carbondioxide. Br Med J 1982;2:117.

8. Holdcroft A. Regional Anaesthetic techniques. Ch 15. In Principles and practice of obstetric anaesthesia and analgesia, Black well science Publishers, 2000:p.243-59.

9. Li DF, Ress GAD, Rosen M. Continuous extradural infusion of $0.0625 \%$ or $0.125 \%$ Bupivacaine for pain relief in primigravid labour. Br J Anaesth 1985;57:264-70.

10. Purdy G, Currie J, Owen H. Continuous extradural analgesia in labour: comparison between on-demand and regular top-up comparison between on- demand and regular topup injections. Br J Anaesth 1987;59:319-24.

11. Justin DM, Francis D, Houlton PG. A controlled trial of extradural fentanyl in labour. Br J Anaesth 1982;54:409-14.

12. Steenbarge VA, Debroux HC, Noorudin H. Extradural bupivacaine with sufentanil for vaginal delivery a doubleblind trial. Br J Anaesth 1987;59:1518-22.

13. Reynolds F, Sullivan GO. Epidural Fentanyl and perineal poin in labour. Anaesthesia 1989;44:341-44.

14. Serutton MJ, Porter JS, O'Sullivan G. Comparison of three loading doses to establish labour analgesia. Int J Obstet Anaesth 1998;7(3):165-9.

15. James KS, McGrady, Quasim J, Patrick., A comparison of epidural bolus administration of $0.25 \%$ Bupivacaine and $0.1 \%$ Bupivacaine with $0.0002 \%$ Fentanyl for analgesia during labour. Br J Anaesth 1998;81:501-10

16. Cohen SE, Tan S, Albright GA, Halpern J. Epidural fentanyl/bupivacaine mixture for obstetric analgesia. Anaesthesia 1987;67:403-07.

17. Wong CA, Scavone BM, Peaceman AM, et al. The risk of cesarean delivery with neuraxial analgesia given early versus late in labour. N Engl J Med 2005; 352(7):655-65.

18. Chestnut DH, Cindy OL, Bates JN, et al, Continuous infusion epidural analgesia during labour-A randomized double blind comparison of $0.625 \%$ Bupivacaine $+0.0002 \%$ Fentanyl versus $0.125 \%$ Bupivacaine. Aanesthesiology 1988;68:754-59.

\begin{tabular}{|c|c|c|c|}
\hline VAS Score & $\begin{array}{c}\text { Group C } \\
(\mathbf{n = 6 0})\end{array}$ & $\begin{array}{c}\text { Group T } \\
(\mathbf{n = 6 0})\end{array}$ & P value \\
\hline I & $8.72 \pm 0.61$ & $0.67 \pm 1.00$ & $<0.001^{* *}$ \\
\hline II & $9.75 \pm 0.44$ & $1.33 \pm 1.55$ & $<0.001^{* *}$ \\
\hline \multicolumn{4}{|c|}{ Table 1: Comparison of Pain score (VAS) between } \\
Two groups in stage 1 and 2 of labour.
\end{tabular}


A significantly lower VAS score was noted in Group T both in stage 1 and 2. Almost all the parturients in Group C had a VAS score of above 8 in stage 1 and above 9 in stage 2.

\begin{tabular}{|c|c|c|c|}
\hline $\begin{array}{c}\text { Duration of labour } \\
\text { in minutes }\end{array}$ & $\begin{array}{l}\text { Group C } \\
(n=60)\end{array}$ & $\begin{array}{c}\text { Group T } \\
(n=60)\end{array}$ & P value \\
\hline Stage I & $425.17 \pm 99.78$ & $469.25 \pm 111.48$ & $0.024 *$ \\
\hline Stage II & $31.02 \pm 15.78$ & $33.75 \pm 17.29$ & 0.368 \\
\hline $\begin{array}{r}\text { Table 2: Compa } \\
\text { Stage of Ic }\end{array}$ & $\begin{array}{l}n \text { of Duration } \\
r \text { in min. bet }\end{array}$ & $\begin{array}{l}\text { labour in } 1^{\text {st }} \text { at } \\
\text { en Two groups. }\end{array}$ & \\
\hline
\end{tabular}

A moderate increase in the duration of stage 1 is seen in Group T as compared to Group C. Duration of labour in stage 2 showed no significant difference.

\begin{tabular}{|c|c|c|c|c|}
\hline & \multicolumn{3}{|c|}{ Apgar Score } & \multirow{2}{*}{$P$ value } \\
\hline & $0-3$ & $4-6$ & $7-10$ & \\
\hline \multicolumn{5}{|l|}{ I minute } \\
\hline - $\quad$ Group C & - & $6(10.0 \%)$ & $54(90.0 \%)$ & \multirow{2}{*}{ NS } \\
\hline - $\quad$ Group T & - & $6(10.0 \%)$ & $54(90.0 \%)$ & \\
\hline \multicolumn{5}{|l|}{5 minute } \\
\hline - $\quad$ Group C & - & 0 & $60(100.0 \%)$ & \multirow{2}{*}{ NS } \\
\hline - $\quad$ Group T & - & $1(1.7 \%)$ & $59(98.3 \%)$ & \\
\hline \multicolumn{5}{|l|}{10 minute } \\
\hline - $\quad$ Group C & - & - & $60(100.0 \%)$ & \multirow{2}{*}{ NS } \\
\hline - $\quad$ Group T & - & - & $60(100.0 \%)$ & \\
\hline
\end{tabular}

At the 1st min. $10 \%(n=6)$ of patients in both groups had an APGAR score of less than 6 . At the 5 th min. $1.7 \%$ (n=1) in Group T and none Group C had an APGAR score of less than 6.

At the 10th min. all the newborns in both the groups had APGAR scores of more than 7.

There was no significant difference between Groups $\mathrm{C}$ and $\mathrm{T}$ with respect to the incidence of fetal distress. 4 (6.7\%) in Group T and $2(3.3 \%)$ in Group C required oxygen, oral suction and

bag mask ventilation. None were intubated or required prolonged ventilation. 2 (3.3\%) new borns in Group T and 1 (1.7\%) new born in Group C were transferred to NICU for observation.

\begin{tabular}{|c|c|c|}
\hline Mode of Delivery & $\begin{array}{c}\text { Group C } \\
\text { (n=60) }\end{array}$ & $\begin{array}{c}\text { Group T } \\
\text { (n=60) }\end{array}$ \\
\hline NVD (normal vaginal delivery) & $41(68.3 \%)$ & $39(65.0 \%)$ \\
\hline LSCS & $17(28.3 \%)$ & $17(28.3 \%)$ \\
\hline FORCEPS & 0 & $3(5.0 \%)$ \\
\hline VACUUM & $2(3.3 \%)$ & $1(1.7 \%)$ \\
\hline & Distribution of Mode of delivery is statistically \\
similar between two groups with \\
Inference
\end{tabular}

The incidence of NVD, LSCS and instrumental deliveries was similar in both groups. In Group 'T’ 12 parturients received tramadol before instituting analgesia (CSE) and none received after instituting analgesia.

No significant difference was obtained in side effects among the groups. Hypotension (more than $10 \%$ drop from baseline) was seen in 6 parturients in Group T, relieved in a short time by left uterine replacement and intravenous fluid resuscitation. Itching that was observed in GroupT did not require treatment. 